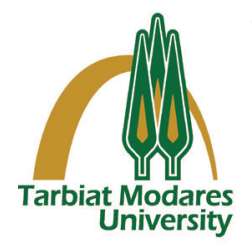

\title{
Comparison of QSOFA Score and SIRS Criteria for the Prediction of Sepsis Outcome in Patients with a Suspected Bacterial Infection outside the Intensive Care Unit in the North of Iran
}

\section{A R T I C L E I N F O}

Article Type

Original Research

Authors

Maryamsadat Mosavi, $M D^{1}$

Lida Mahfoozi, $M D^{2^{*}}$

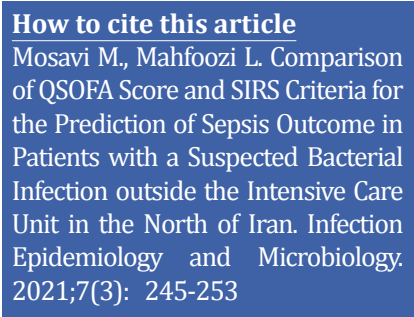

${ }^{1}$ Soltanieh Clinic, Soltanieh, Zanjan, Iran.

${ }^{2}$ Department of Health, Nutrition, and Infectious Diseases, school of medicine, Guilan University of Medical Sciences, Rasht, Iran

\section{* Correspondence}

Address: Department of Health, Nutrition, and Infectious Diseases, Guilan University of Medical Sciences, Rasht, Iran

drlidamahfoozi@yahoo.com

\section{A B S T R A C T}

Backgrounds: The present study aimed to determine the quick Sepsis-related Organ Failure Assessment (qSOFA) score in comparison with systemic inflammatory response syndrome (SIRS) criteria to predict adverse consequences of a suspected bacterial infection in patients outside the intensive care unit (ICU).

Materials \& Methods: This retrospective study was conducted on patients during March 2018 to March 2019. All hospitalized patients with this suspected infection were positive for both SIRS and microbial cultures. Demographic and laboratory variables were recorded for all patients to determine the presence and time of various components of both SIRS criteria and the qSOFA score.

Findings: Out of 128 patients with suspected sepsis, 87 (68\%) patients were confirmed to have septicemia based on SIRS criteria. SIRS criteria classified $68 \%$ of patients in the sepsis group (87 of 128), of which $39(44.8 \%$ ) had a positive qSOFA score. The sensitivity and specificity ratios of qSOFA were 44.83 and $80.49 \%$, respectively.

Receiver operating characteristic (ROC) curve analysis results showed that the area under the ROC curve (AUC) of pSOFA scores for predicting sepsis patients was not significantly different. Moreover, regarding the sepsis-related mortality, the area under ROC showed that qSOFA criteria (score $\geq 2$ ) were able to predict mortality in patients with $71 \%$ sensitivity and $72 \%$ specificity.

Conclusion: This study findings revealed that the qSOFA score was significantly efficient in predicting mortality. However, SIRS criteria were more sensitive than the qSOFA score in predicting the definitive diagnosis of sepsis. Therefore, the qSOFA score seems to be an invaluable tool for predicting outcome in sepsis patients.

\section{Keywords: Sepsis, SIRS, qSOFA, Bacterial infection}

\section{CITATION LINKS}

[1] Sakr Y, Jaschinski U, Wittebole X, Szakmany T, Lipman J, Namendys-Silva SA, et al. Sepsis in ... [2] Vincent JL, Jones G, David S, Olariu E, Cadwell KK. Frequency and ... [3] Sedigh ESH, Motamedifar M, Mansury D, Halaji M, Hashemizadeh Z, Ali MY. Bacterial ... [4]Martín S, Pérez A, Aldecoa C. Sepsis and immunosenescence in the elderly ... [5] Ghassabi F, Hashempour T, Moghadami M, Davarpanah MA, Kalani M, Chatrabnous N, et al. Bacterial etiology and antibiotic resistance pattern of septicemia in HIV and non-HIV patients admitted to tertiary care ... [6]Martins FS, Guedes GG, Santos TM, de Carvalho-Filho MA. Suspected infection in ... [7] Singer M, Deutschman CS, Seymour CW, Shankar-Hari M, Annane D, Bauer M, et al. The third international consensus ... [8] Tian H, Zhou J, Weng L, Hu X, Peng J, Wang C, et al. Accuracy of qSOFA for the diagnosis of ... [9] Sartelli M, Kluger Y, Ansaloni L, Hardcastle TC, Rello J, Watkins RR, et al. Raising concerns ... [10] Seymour CW, Lui VX, Iwashyna TJ, Brunkhorst FM, Rea TD, Scherag A, et al. Assessment of ... [11] Nakayama I, Izawa J, Mouri H, Kitamura T, Shiotsuka J. Mortality and detailed characteristics of ... [12] Jiang J, Yang J, Mei J, Jin Y, Lu Y. Head-to-head comparison of qSOFA and SIRS criteria in ... [13] Chakraborty RK, Burns B. Systemic inflammatory response ... [14]Cao C, Yu M, Chai Y. Pathological alteration and therapeutic implications of ... [15] Andaluz D, Ferrer R. SIRS, qSOFA, and organ failure for assessing sepsis at the ... [16] Serafim R, Gomes JA, Salluh J, Póvoa P. A comparison of the quick-SOFA and systemic ... [17] Askim Å, Moser F, Gustad LT, Stene H, Gundersen M, Åsvold BO, et al. Poor performance of ... [18]Sinto R, Suwarto S, Lie KC, Harimurti K, Widodo D, Pohan HT. Prognostic accuracy of the quick sequential organ failure assessment (qSOFA)-lactate criteria for mortality in adults with suspected bacterial infection in ... [19] Shahsavarinia K, Moharramzadeh P, Arvanagi RJ, Mahmoodpoor A. qSOFA score for ... [20]Marik PE, Taeb AM. SIRS, qSOFA and new sepsis ... [21]Williams JM, Greenslade JH, McKenzie JV, Chu K, Brown AF, Lipman J. Systemic inflammatory response ... [22]Finkelsztein EJ, Jones DS, Ma KC, Pabón MA, Delgado T, Nakahira K, et al. Comparison of ... [23]Churpek MM, Snyder A, Han X, Sokol S, Pettit N, Howell MD, et al. Quick sepsis-related organ ... [24]Haydar S, Spanier M, Weems P, Wood S, Strout T. Comparison of QSOFA score and SIRS criteria as ... 


\section{Introduction}

Sepsis is a critical condition accounting for $10 \%$ of intensive care unit (ICU) cases and 10 to 20 $\%$ of in-hospital mortality rates worldwide ${ }^{[1-3]}$. In the last few decades, the incidence of sepsis and severe sepsis has increased probably due to the fact that they are more easily diagnosed in elderly patients ${ }^{[4-5]}$.

Rapid detection of sepsis could lead to early intervention, which has attracted much attention in the emergency department (ED). To diagnose sepsis based on the former consensus explanations, the criteria of the infection and two or more criteria of systemic inflammatory response syndrome (SIRS) must be met ${ }^{[6-7]}$. Tachypnea (respiratory rate of over 20 breaths per minute), leukopenia or leukocytosis (leucocyte count of higher than 12,000 cells $/ \mu \mathrm{L}$ or $<4000 / \mu \mathrm{L}$ ), tachycardia (heart rate of over 90 beats per minutes), and hypothermia or fever (body temperature of less than $36^{\circ} \mathrm{C}$ or higher than $38^{\circ} \mathrm{C}$, respectively) are four SIRS criteria ${ }^{[6]}$. Nevertheless, SIRS has been criticized for its prognostic value, utility, and inadequate specificity ${ }^{[6]}$.

Currently, an international task force in the third international consensus explanations has redefined this syndrome as septic shock (Sepsis-3) and sepsis ${ }^{[7]}$. Accordingly, sepsis is considered as a life-threatening organ dysfunction resulted from a dysregulated reaction of host to infection. An acute increase of at least two points in the sequential organ failure assessment (SOFA) score is characterized as organ dysfunction ${ }^{[5]}$.

The use of the quick sepsis-related organ failure assessment (qSOFA) tool has also been redefined in recent Sepsis- 3 guidelines. Studies have indicated that the qSOFA score is more accurate in predicting death outside the ICU than the SIRS score ${ }^{[8]}$. In Sepsis-3, qSOFA criteria screening is recommended to be perform outside the ICU to encourage clinicians to further assess organ dysfunction and initiate an appropriate therapy ${ }^{[9]}$.

Novel criteria of qSOFA have been represented in Sepsis-3 (qSOFA scores in the range of $0-3$; receiving 1 point if meeting the following criteria: altered mental status, respiratory rate $>21$ breaths/min, and systolic blood pressure of less than or equal to $100 \mathrm{mmHg})^{[10]}$.

Longer ICU stay and higher mortality risk are predicted by a qSOFA score of $\geq 2^{[11]}$. The explanation group has described qSOFA as a better predictor of mortality compared to SIRS, suggesting that a qSOFA score of 2 or higher be used rather than a SIRS score of $\geq 2$ to identify infected patients at higher risk of death ${ }^{[12]}$. Both early diagnosis and treatment of sepsis are necessary to decrease mortality and hospital stay length. The novel explanation could improve the treatment of patients with more severe sepsis.

Objectives: The present study aimed to determine the effectiveness of qSOFA compared to SIRS in predicting adverse consequences for suspected sepsis patients outside the ICU.

\section{Materials and Methods}

Study design and patient population: This cross-sectional study was conducted on patients referring to the emergency medicine department of Razi hospital during March 2018 to March 2019. All hospitalized patients with a suspected infection, who were positive for SIRS and microbial cultures (blood, urine, and CSF) or/and received antibiotics within $48 \mathrm{hrs}$ of admission to ED, were enrolled in this study. Patients were considered as sepsis positive if they met two or more of SIRS criteria. Suspected infection was diagnosed using the following data extracted from patients' hospital records: blood pressure, heart rate, body temperature, respiratory rate, and level of consciousness. Patients who did not have demographic and laboratory variables as 
Table 1) Baseline characteristics and clinical outcomes of patients.

\begin{tabular}{lll}
\hline Variable & $\begin{array}{l}\text { Patients with Definitive Sepsis } \\
\mathbf{N}(\%)\end{array}$ & $\begin{array}{l}\text { Patients without Sepsis } \\
\mathbf{N}(\%)\end{array}$ \\
\hline Male & $44(50.6)$ & $16(39)$ \\
\hline Female & $43(49.4)$ & $25(61)$ \\
\hline SBP & $115 \pm 21.5$ & $120.4 \pm 22.1$ \\
\hline DBP & $69.6 \pm 10.3$ & $70.6 \pm 10.01$ \\
\hline PR & $91.5 \pm 14.6$ & $86.7 \pm 13.8$ \\
\hline RR & $18.5 \pm 5.01$ & $18.1 \pm 4.5$ \\
\hline T & $38.4 \pm 0.5$ & $38.07 \pm 0.5$ \\
\hline WBC & $15621.8 \pm 4413.3$ & $13963.4 \pm 3138.1$ \\
\hline PT & $12.3 \pm 0.8$ & $12.2 \pm 0.41$ \\
\hline PTT & $29.2 \pm 1.8$ & $28.6 \pm 1.2$ \\
\hline BUN & $29.5 \pm 10.3$ & $26.5 \pm 8.6$ \\
\hline CR & $2.6 \pm 1.07$ & $1.2 \pm 0.37$ \\
\hline Type of infection* & & \\
\hline Pneumonia & $37(46.8)$ & $13(48.1)$ \\
\hline UTI & $21(26.6)$ & $11(40.7)$ \\
\hline Intra-abdominal infection & $7(8.9)$ & 0 \\
\hline SSTIs & $14(17.7)$ & $3(11.1)$ \\
\hline
\end{tabular}

UTI: urinary tract infection, SSTIs: skin and soft tissue infections, SBP: systolic blood pressure, DBP: diastolic blood pressure, PR: progesterone-receptor, RR: respiratory rate, T: troponin, PT: prothrombin time, PTT: partial thromboplastin time, BUN: blood urea nitrogen; CR: creatinine $* p=.23$

well as SIRS criteria were excluded from the study ${ }^{[13]}$. After final diagnosis, patients were divided into two groups (with and without sepsis). Then qSOFA criteria in these two groups were evaluated, and the number of patients diagnosed with sepsis based on qSOFA and SIRS criteria was compared. In addition, SIRS criteria served as the gold standard in the diagnosis of sepsis.

Data extraction protocol: Demographic information, comorbidities, vital signs, site of infection, clinical variables, and laboratory results were recorded in a data collection form designed for the study. All data were extracted from the electronic medical record system in the first affiliated Razi Hospital to Guilan Medical University. In this regard, patients' vital signs were used to determine both SIRS criteria and the qSOFA score.

\section{Findings}

Characteristics of the study subjects: During one year of study, out of 128 patients with suspected sepsis, 87 (68\%) patients were diagnosed with septicemia based on SIRS criteria. The median age of subjects was $72.8 \pm 15.9$ years; of whom $50.6 \%$ (44 of 87 ) were male. There was no significant difference between the mean ages of both sexes. Table 1 shows the baseline characteristics and clinical outcomes of patients.

Accordingly, pneumonia (46.8 and 48.1\%) and urinary tract infection (26.6 and 40.7\%) 

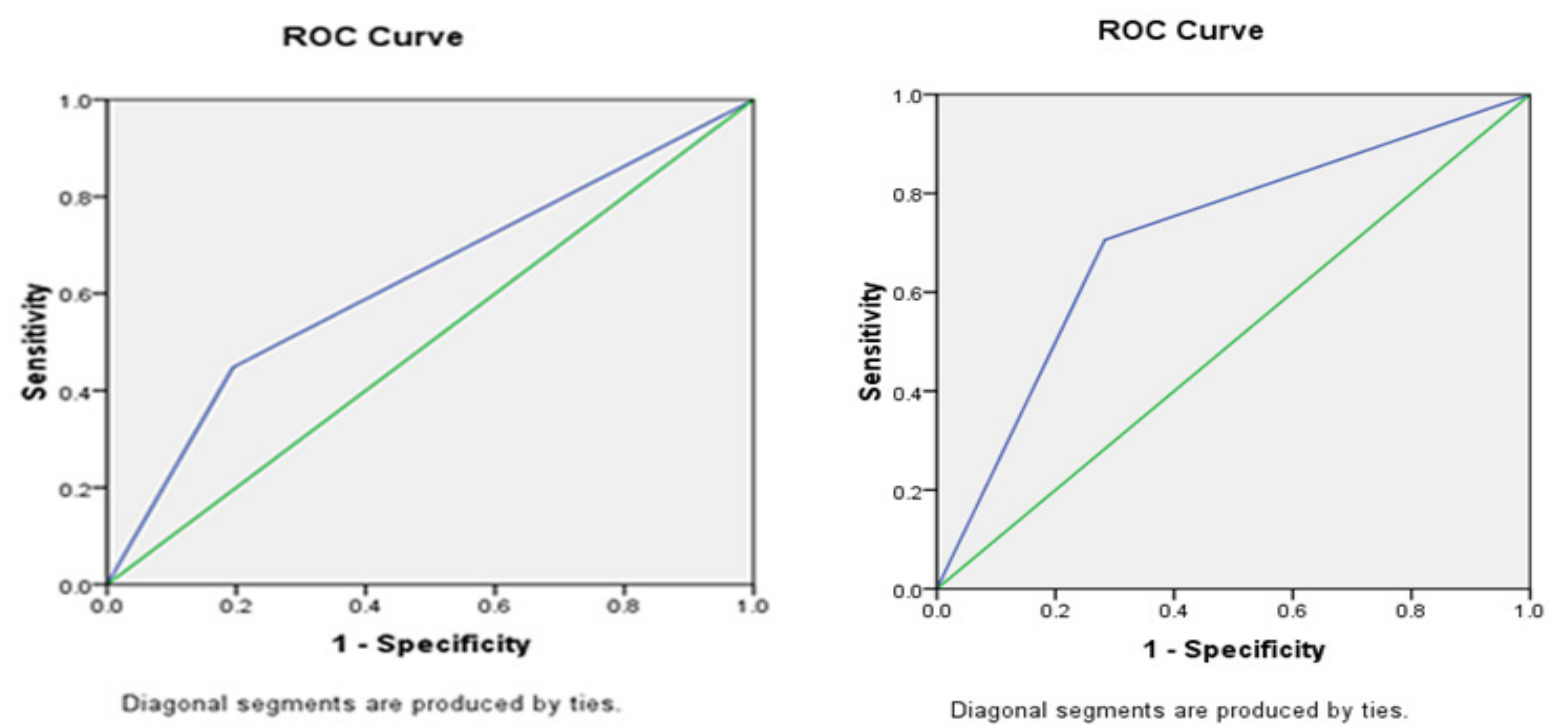

Fig. 1) Prediction of outcome by qSOFA for diagnosis of sepsis and mortality

were the most common infections among sepsis and non-sepsis patients, respectively. However, there was no significant relationship between the site of infection and sepsis $(p=.22)$

Of 87 SIRS positive patients, 39(44.8\%) and $48(55.2 \%)$ had positive and negative qSOFA scores, respectively. In this regard, there was a significant correlation between the qSOFA scores and sepsis $(p=.006)$.

The sensitivity and specificity ratios of qSOFA were $44.83 \%$ (95\% CI: 34.15 to $55.87 \%$ ) and $80.49 \%$ (95\% CI: 65.13 to $91.18 \%$ ), respectively. Table 2 summarizes the sensitivity and specificity of the qSOFA index according to comorbidities.

Sensitivity analysis: ROC curve analysis results showed that the area under the ROC curve (AUC) of qSOFA scores for predicting sepsis patients was not significantly different (0.627, $p=.021)$ (Figure 1A). Moreover, regarding the sepsis-related mortality, the area under ROC showed that qSOFA criteria (score $\geq 2$ ) were able to predict mortality in patients (AUC, $0.71 ; p<.001$ ) with $71 \%$ sensitivity and $72 \%$ specificity (Figure 1B). Thirty-four (34 of 87) patients with definitive sepsis died during hospitalization. Out of 34 expired patients, $24(70.5 \%)$ and $10(29.4 \%)$ were positive and negative for the qSOFA score during hospitalization, respectively. Accordingly, a significant correlation was observed between mortality in sepsis patients (SIRS criteria) and qSOFA score results ( $p \geq .001)$. The qSOFA score results for the diagnosis of sepsis patients with comorbidities are shown in Table 2 .

There was a statistically significant correlation between sepsis and hypertension $(p=.006)$, diabetes $(p=.027)$, ischemic heart disease (IHD) ( $p=.018)$, and results of qSOFA score. In this regard, no significant correlation was found between sepsis and chronic obstructive pulmonary disease (COPD) $(p=.46)$, cerebrovascular accident (CVA) ( $p=.98)$, chronickidney disease (CKD) ( $p=.98)$, cancer $(p=.16)$, and results of qSOFA score. Moreover, the sensitivity of the qSOFA score in the diagnosis of sepsis was 80, 69.2, 55.3, and $46 \%$ in CVA, IHD, hypertension, and diabetes patients with SIRS-positive sepsis, respectively. The specificity and sensitivity of the qSOFA index in the diagnosis of sepsis according to the aforementioned diseases are 
Table 2) qSOFA score results for the diagnosis of sepsis patients with comorbidityq

\begin{tabular}{|c|c|c|c|c|c|c|}
\hline qSOFA score & $\begin{array}{l}\text { Sensitivity } \\
(95 \% \mathrm{CI})\end{array}$ & $\begin{array}{l}\text { Specificity } \\
(95 \% \mathrm{CI})\end{array}$ & $\begin{array}{l}\text { Disease } \\
\text { Prevalence }\end{array}$ & $\begin{array}{l}\text { Positive } \\
\text { Predictive Value } \\
(95 \% \text { CI })\end{array}$ & $\begin{array}{l}\text { Negative } \\
\text { Predictive Value } \\
(95 \% \text { CI })\end{array}$ & $\begin{array}{l}\text { Accuracy } \\
(95 \% \mathrm{CI})\end{array}$ \\
\hline Total patients & $\begin{array}{l}44.83 \\
(34.15-55.87)\end{array}$ & $\begin{array}{l}80.49 \\
(65.13-91.18)\end{array}$ & $\begin{array}{l}67.97 \% \\
\text { ( } 59.15 \text { to } 75.94)\end{array}$ & $\begin{array}{l}82.98 \\
(71.51-90.45)\end{array}$ & $\begin{array}{l}40.74 \\
(35.05-46.69)\end{array}$ & $\begin{array}{l}56.25 \\
(47.21-65)\end{array}$ \\
\hline $\begin{array}{l}\text { Patients with } \\
\text { hypertension }\end{array}$ & $\begin{array}{l}55.36 \\
(41.47-68.66)\end{array}$ & $\begin{array}{l}76.92 \\
(56.35-91.03)\end{array}$ & $\begin{array}{l}68.29 \% \\
\text { (57.08 to } 78.13 \text { ) }\end{array}$ & $\begin{array}{l}83.78 \\
(71.14-91.55)\end{array}$ & $\begin{array}{l}44.44 \\
(35.83-53.41)\end{array}$ & $\begin{array}{l}62.20 \\
(50.81-72.68)\end{array}$ \\
\hline $\begin{array}{l}\text { Patients with } \\
\text { diabetic }\end{array}$ & $\begin{array}{l}46 \\
(31.81-60.68)\end{array}$ & $\begin{array}{l}84.21 \\
(60.42-96.62)\end{array}$ & $\begin{array}{l}72.46 \% \\
(60.38 \text { to } 82.54)\end{array}$ & $\begin{array}{l}88.46 \\
(72.23-95.76)\end{array}$ & $\begin{array}{l}37.21 \\
(30.05-44.97)\end{array}$ & $\begin{array}{l}56.52 \\
(44.04-68.42)\end{array}$ \\
\hline $\begin{array}{l}\text { Patients with } \\
\text { IHD }\end{array}$ & $\begin{array}{l}69.23 \\
(52.43-82.98)\end{array}$ & $\begin{array}{l}64.71 \\
(38.33-85.79)\end{array}$ & $\begin{array}{l}69.64 \% \\
\text { (55.90 to 81.22) }\end{array}$ & $\begin{array}{l}81.82 \\
(69.58-89.85)\end{array}$ & $\begin{array}{l}47.83 \\
(33.75-62.25)\end{array}$ & $\begin{array}{l}67.86 \\
(54.04-79.71)\end{array}$ \\
\hline \multicolumn{3}{|c|}{ Patients with CVA80 (56.34- 94.27) 0 (0-70.76) } & $\begin{array}{l}86.96 \% \\
(66.41 \text { to } 97.22)\end{array}$ & $\begin{array}{l}84.21 \\
(81.07-86.91)\end{array}$ & 0 & $\begin{array}{l}69.57 \\
(47.08-86.79)\end{array}$ \\
\hline
\end{tabular}

SOFA: quick SOFA, IHD: ischemic heart disease, CVA: cerebrovascular accident

Table 3) Specificity and sensitivity of the qSOFA index in the diagnosis of sepsis according to the comorbidity

\begin{tabular}{|c|c|c|c|}
\hline \multicolumn{2}{|c|}{ Sepsis and Comorbidity } & \multirow{2}{*}{$\begin{array}{l}\text { Negative-qSOFA N (\%) } \\
25 \text { (55.6) }\end{array}$} & \multirow{2}{*}{$\begin{array}{l}\text { Positive- qSOFA N (\%) } \\
31(83.8)\end{array}$} \\
\hline c - i l & Yes & & \\
\hline & No & $20(44.4)$ & $6(16.2)$ \\
\hline \multirow{2}{*}{ Sepsis + diabetic } & Yes & $27(62.8)$ & $23(88.5)$ \\
\hline & No & $16(37.2)$ & $3(11.5)$ \\
\hline \multirow{2}{*}{ Sepsis + IHD } & Yes & $12(52.2)$ & $27(81.8)$ \\
\hline & No & $11(47.8)$ & $6(18.2)$ \\
\hline \multirow{2}{*}{ Sepsis + COPD } & Yes & $3(50)$ & $2(100)$ \\
\hline & No & $3(50)$ & 0 \\
\hline \multirow{2}{*}{ Sepsis + CVA } & Yes & $4(100)$ & $16(84.2)$ \\
\hline & No & 0 & $3(15 . .8)$ \\
\hline \multirow{2}{*}{ Sepsis + cirrhosis } & Yes & 0 & $1(100)$ \\
\hline & No & 0 & 0 \\
\hline \multirow{2}{*}{ Sepsis + cancer } & Yes & $10(90.9)$ & 0 \\
\hline & No & $1(9.1)$ & $1(100)$ \\
\hline \multirow{2}{*}{ Sepsis + CKD } & Yes & $2(100)$ & $5(83.3)$ \\
\hline & No & 0 & $1(16.7)$ \\
\hline
\end{tabular}


presented in Table 3.

\section{Discussion}

Sepsis is a clinical condition leading to organ dysfunction. It is caused by the host's excessive inflammatory response to infection ${ }^{[14]}$. There is neither gold standard nor diagnostic criteria to define the diagnosis or prognosis of sepsis. For easier evaluation in the hospital, the qSOFA score has been established to help recognize suspected sepsis patients who appear to have a poor prognosis ${ }^{[15]}$. Recently, several studies have been conducted to confirm the validity and performance of qSOFA in identifying patients with poor sepsis prognosis and diagnosis compared to SIRS criteria ${ }^{[15-16]}$.

Given the establishment of new criteria and comprehensive use of qSOFA for the diagnosis of sepsis in several studies around the world with different results, this retrospective descriptive study aimed to compare the two criteria of qSOFA and qSOFA in identifying sepsis patients in order for timely diagnosis and selection of an appropriate treatment method. The present study results could assist healthcare staff to determine an appropriate pattern to improve the treatment of sepsis patients and reduce false-positive cases.

According to this study results, $68 \%$ (87 of 128) of patients were definitely diagnosed with sepsis based on SIRS criteria. Also, the positive predictive value of SIRS criteria for the diagnosis of sepsis was $68 \%$. On the other hand, SIRS criteria classified $68 \%$ of patients in the sepsis group, of which 44.8 and $55.2 \%$ had positive and negative qSOFA scores, respectively. Therefore, the results showed that $44.8 \%$ of confirmed sepsis patients had positive qSOFA scores. This means that, in every two sepsis patients, one does not meet the qSOFA criteria.

In this regard, the sensitivity and specificity ratios of qSOFA were 44.83 and $80.49 \%$, respectively. Also, there was a significant correlation between the qSOFA score and sepsis $(p=.006)$. However, SIRS criteria were more sensitive than the qSOFA score in the diagnosis of sepsis.

In a meta-analysis study, Serafim, et al. found that SIRS criteria were more sensitive than qSOFA criteria in diagnosing sepsis [16]. Among the studies reviewed, only one study comparing the sensitivity of SIRS (84.4\%) and qSOFA (97.3\%) showed a better specificity for qSOFA in the diagnosis of infection [16].

In another study on 108 severe sepsis patients in the emergency department, a qSOFA score of $\geq 2$ was able to identify only $15.4 \%$ of patients compared with a SIRS score $\geq 2$ identifying $65.4 \%$ of patients ${ }^{[17]}$. The lower sensitivity of qSOFA in the diagnosis of sepsis raises concerns regarding the potential delays in sepsis identification and treatment ${ }^{[16]}$. In the present study, SIRS criteria were better in the diagnosis of sepsis than qSOFA.

However, according to the literature, the gold standard for the diagnosis of sepsis is not available; therefore, the physician could rely on the intersection of three groups of clinical and laboratory data, including general systemic manifestations, organ dysfunction/ failure manifestations, and microbiological documentation [16, 18-19].

Recently, the new definition of sepsis has clearly centered on the organ dysfunction, which is why the Sepsis-3 task force designed a new tool, qSOFA (respiratory rate $>22$ / min, systolic blood pressure $<100 \mathrm{~mm} \mathrm{Hg}$, altered mentation) [7, 20-21].

This study findings showed a significant relationship between mortality in sepsis patients and qSOFA score results. The ability of qSOFA to predict mortality in SIRS-positive sepsis patients was $61.5 \%$, indicating its significant efficacy in predicting mortality (based on AUC analysis). In addition, the 
sensitivity and specificity of qSOFA criteria were 71 and $72 \%$ for predicting sepsisrelated mortality.

Thus, this study findings may contribute to the accumulation of evidence on the potential clinical usefulness of qSOFA in the prediction of mortality. This finding is in line with the finding of another recently published large retrospective study [22-23]. In a study conducted by Heydar et al. (2017), the sensitivity of SIRS and qSOFA criteria to correctly identify in-hospital mortality was 95.5 and $90.1 \%$, respectively ${ }^{[24]}$. Moreover, their specificity was 5.6 and $45.7 \%$, respectively ${ }^{[24]}$. In the present study, a significant correlation was found between sepsis and hypertension $(p=.006)$, diabetic ( $p=.027), \operatorname{IHD}(p=.018)$, and qSOFA criteria. The results showed different sensitivities and specificities for qSOFA criteria among confirmed sepsis patients with comorbidities.

Among patients with comorbidities, the highest sensitivity of positive qSOFA score in the diagnosis of sepsis was among CVA patients $(80 \%)$, followed by IHD patients (69.2\%), while the highest specificity was among patients with diabetes (84.2\%) and hypertension (76.9\%).

\section{Conclusions}

There was no significant difference in the site of infection between patients with sepsis. This study findings revealed that the qSOFA score was significantly efficient in predicting mortality. These results may help clinicians obtain further insight into the usefulness of qSOFA. However, SIRS criteria are more sensitive than the qSOFA score in predicting the definite diagnosis of sepsis. Therefore, the qSOFA score seems to be an invaluable tool for predicting outcome in sepsis patients in ED.

Acknowledgments: Not applicable.

Ethical permission: This study was supported by Guilan University of Medical Science (Grant No: 12563).

Conflicts of interests: The authors declare that they have no conflicts of interest.

Authors' contribution: Conceptualization: LM and MM; Data curation and formal analysis: LM and MM; Investigation: LM and MM; Methodology and project administration: LM and MM; Supervision: LM and MM; Validation: LM and MM; Writing of original draft: LM and MM; Writing, reviewing, and editing LM and MM.

Fundings: Self-Funding

Consent to participate: Consent form was obtained from all healthy people.

\section{References}

1. Sakr Y, Jaschinski U, Wittebole $X$, Szakmany T, Lipman J, Ñamendys-Silva SA, et al. Sepsis in intensive care unit patients: Worldwide data from the intensive care over nations audit. In: Open forum infectious diseases. US: Oxford University Press; 2018,5(12):ofy313.

2. Vincent JL, Jones G, David S, Olariu E, Cadwell KK. Frequency and mortality of septic shock in Europe and North America: A systematic review and metaanalysis. Crit Care. 2019;23(1):1-1.

3. Sedigh ESH, Motamedifar M, Mansury D, Halaji M, Hashemizadeh Z, Ali MY. Bacterial etiology and antibacterial susceptibility patterns of pediatric bloodstream infections: A two year study from Nemazee hospital, Shiraz, Iran. J Compr Ped. 2016;7(1):e29929.

4. Martín S, Pérez A, Aldecoa C. Sepsis and immunosenescence in the elderly patient: A Review. Front Med. 2017;4:20.

5. Ghassabi F, Hashempour T, Moghadami M, Davarpanah MA, Kalani M, Chatrabnous $\mathrm{N}$, et al. Bacterial etiology and antibiotic resistance pattern of septicemia in HIV and non-HIV patients admitted to tertiary care hospitals, Shiraz, South of Iran. Cell 
Mol Biol. 2017;63(9):115-21.

6. Martins FS, Guedes GG, Santos TM, de Carvalho-Filho MA. Suspected infection in afebrile patients: Are they septic? Medicine. 2017;96(10):e6299.

7. Singer M, Deutschman CS, Seymour CW, Shankar-Hari M, Annane D, Bauer M, et al. The third international consensus definitions for sepsis and septic shock (Sepsis-3). Jama. 2016;315(8):801-10.

8. Tian H, Zhou J, Weng L, Hu X, Peng J, Wang C, et al. Accuracy of qSOFA for the diagnosis of Sepsis-3: A secondary analysis of a population-based cohort study. J Thorac Dis. 2019;11(5):2034-42.

9. Sartelli M, Kluger Y, Ansaloni L, Hardcastle TC, Rello J, Watkins RR, et al. Raising concerns about the Sepsis-3 definitions. World J Emerg Surg. 2018;13(1):1-9.

10. Seymour CW, Lui VX, Iwashyna TJ, Brunkhorst FM, Rea TD, Scherag A, et al. Assessment of clinical criteria for sepsis: For the third international consensus definitions for sepsis and septic shock (Sepsis-3). Jama. 2016;315(8):762-74.

11. Nakayama I, Izawa J, Mouri H, Kitamura T, Shiotsuka J. Mortality and detailed characteristics of pre-ICU qSOFA-negative patients with suspected sepsis: An observational study. Ann Intensive Care. 2018;8(1):1-9.

12. Jiang J, YangJ, Mei J, Jin Y, Lu Y.Head-to-head comparison of qSOFA and SIRS criteria in predicting the mortality of infected patients in the emergency department: A meta-analysis. Scand J Trauma Resusc Emerg Med. 2018;26(1):1-1.

13. Chakraborty RK, Burns B. Systemic inflammatory response syndrome. Treasure Island (FL): StatPearls Publishing; 2021.

14. Cao C, Yu M, Chai Y. Pathological alteration and therapeutic implications of sepsisinduced immune cell apoptosis. Cell Death Dis. 2019;10(10):1-4.
15. Andaluz D, Ferrer R. SIRS, qSOFA, and organ failure for assessing sepsis at the emergency department. J Thorac Dis. 2017;9(6):1459-62.

16. Serafim R, Gomes JA, Salluh J, Póvoa P. A comparison of the quick-SOFA and systemic inflammatory response syndrome criteria for the diagnosis of sepsis and prediction of mortality: A systematic review and meta-analysis. Chest. 2018;153(3):646-55.

17. Askim Å, Moser F, Gustad LT, Stene H, Gundersen M, Åsvold BO, et al. Poor performance of quick-SOFA (qSOFA) score in predicting severe sepsis and mortality: A prospective study of patients admitted with infection to the emergency department. Scand J Trauma Resusc Emerg Med. 2017;25(1):1-9.

18. Sinto R, Suwarto S, Lie KC, Harimurti K, Widodo D, Pohan HT. Prognostic accuracy of the quick sequential organ failure assessment (qSOFA)-lactate criteria for mortality in adults with suspected bacterial infection in the emergency department of a hospital with limited resources. Emerg Med J. $2020 ; 37(6): 363-9$.

19. Shahsavarinia K, Moharramzadeh $P$, Arvanagi RJ, Mahmoodpoor A. qSOFA score for prediction of sepsis outcome in emergency department. Pak J Med Sci. 2020;36(4):668-72.

20. Marik PE, Taeb AM. SIRS, qSOFA and new sepsis definition. J Thorac Dis. 2017;9(4):943-5.

21. Williams JM, Greenslade JH, McKenzie JV, Chu K, Brown AF, Lipman J. Systemic inflammatory response syndrome, quick sequential organ function assessment, and organ dysfunction: Insights from a prospective database of ED patients with infection. Chest. 2017;151(3):586-96.

22. Finkelsztein EJ, Jones DS, Ma KC, Pabón MA, Delgado T, Nakahira K, et al. Comparison 
of qSOFA and SIRS for predicting adverse outcomes of patients with suspicion of sepsis outside the intensive care unit. Crit Care. 2017;21(1):1-0.

23. Churpek MM, Snyder A, Han X, Sokol S, Pettit N, Howell MD, et al. Quick sepsisrelated organ failure assessment, systemic inflammatory response syndrome, and early warning scores for detecting clinical deterioration in infected patients outside the intensive care unit. Am J Respir Crit Care Med. 2017;195(7):906-11.

24. Haydar S, Spanier M, Weems P, Wood S, Strout T. Comparison of QSOFA score and SIRS criteria as screening mechanisms for emergency department sepsis. Am J Emerg Med. 2017;35(11):1730-3. 